\title{
A PRÁTICA DA CURRICULARIZAÇÃO DA EXTENSÃO NO CURSO DE DIREITO DA UFN: O PROJETO INTEGRADOR E OS SUBPROJETOS
}

\author{
THE PRACTICE OF EXTENSION CURRICULARIZATION IN THE UFN \\ LAW COURSE: THE INTEGRATING PROJECT AND SUBPROJECTS
}

\author{
Liege Alendes de Souza ${ }^{1}$
}

\section{RESUMO}

O presente artigo tem por objetivo abordar a implementação da curricularização da extensão no curso de Direito da Universidade Franciscana, buscando atender as determinações da Resolução número 7, de 18 de dezembro de 2018, do Ministério da Educação. Para tanto, serão apresentados o projeto integrador e os subprojetos desenvolvidos no período de 2020, bem como os resultados alcançados, e as dificuldades impostas diante da decretação pela Organização Mundial da Saúde da pandemia da Covid-19. Desse modo, primeiramente serão referenciadas as legislações aplicáveis ao caso para, em um segundo momento, mostrar a construção do projeto integrador do curso e, a partir daí, o desenvolvimento dos subprojetos. Na parte final, serão discutidos os resultados apresentados nas disciplinas que integram o eixo da curricularização do curso de Direito. O método de abordagem utilizado foi o dedutivo, pois a partir da legislação foi elaborado o projeto integrador do curso e, só então, estruturados os subprojetos das disciplinas extensionistas. O método de procedimento foi o monográfico, porquanto lastreado em doutrina e legislação, assim como no material produzido pelos envolvidos. Como resultados obtidos, pode-se afirmar que o curso de Direito e seus professores e alunos conseguiram superar o período de crise instalado pela pandemia, construindo subprojetos vanguardistas, que cumpriram de forma excelente com as determinações do Ministério da Educação, reinventando a prática extensionista e provando que os períodos de crise são campo fértil para saídas criativas e inovadoras.

Palavras-chave: curricularização da extensão, ensino-pesquisa-extensão, projeto integrador, subprojetos.

\section{ABSTRACT}

This article aims to address the implementation of the extension curriculum in the Franciscan University Law course, seeking to meet the determinations of Resolution number 7, of December 18, 2018, of the Ministry of Education. To this end, the integrative project and the subprojects developed in the 2020 period will be presented, as well as the results achieved, and the difficulties imposed by the World Health Organization's decree on the Covid-19 pandemic. In this way, the legislation applicable to the case is referenced to, in a second moment it shows the construction of the course's integrative project and, from there, it shows the development of the subprojects. In the final part, the results presented in the subjects that integrate the axis of the curricularization of the Law course will be discussed. The method of approach used was the deductive one, since the course's integrative project was elaborated from the legislation and, only then, the subprojects of the extension disciplines were structured. The method of procedure was monographic, as it was based on doctrine and legislation, as well as on the material produced by those involved. As the results obtained, the Law course and its teachers and students managed to overcome the period of crisis installed by the pandemic, building avant-garde subprojects, which excellently complied with the Ministry of Education's determinations, reinventing the extension and proving that periods of crisis are fertile ground for creative and innovative solutions.

Keywords: extension, teaching-research-extension, integrative project, subprojects.

1 Professora do curso de Direito da Universidade Franciscana. E-mail: liegealendes@gmail.com. 


\section{INTRODUÇÃO}

O Ministério da Educação - MEC, por meio da Resolução número 7, de 18 de dezembro de 2018, estabeleceu as diretrizes para a extensão na educação superior brasileira. Tal resolução, em seu artigo $3^{\circ}$, determina que a extensão na educação superior é atividade que se integra à matriz curricular e à organização da pesquisa, constituindo-se em processo interdisciplinar, político educacional, cultural, científico e tecnológico que promove a interação transformadora entre as instituições de ensino superior e os outros setores da sociedade, por meio da produção e da aplicação do conhecimento, em articulação permanente com o ensino e a pesquisa. A resolução, em seu artigo 19, estabeleceu o prazo de três anos para que as instituições de ensino superior implementassem essas diretrizes em seus cursos e atualizassem seus documentos institucionais (Projeto de Desenvolvimento Institucional - PDI, Projeto Político Pedagógico dos Cursos - PPC, entre outros).

Deste modo, visando cumprir com o estabelecido, o Curso de Direito da Universidade Franciscana - UFN, formulou o seu Projeto de Extensão Integrador, intitulado: "Direito constitucional aplicado, gestão de pessoas e processos". Esse projeto é um parâmetro geral, que apresenta a justificativa, os objetivos, a metodologia de trabalho, as pessoas beneficiadas, as entidades parceiras e os territórios a serem explorados na prática da curricularização da extensão no âmbito do curso. A partir da definição do projeto integrador, foram escolhidas, pelo Núcleo Docente Estruturante - NDE, quais as disciplinas se adequavam a proposta e que, a partir de então, passariam a integrar o eixo das disciplinas da curricularização da extensão.

Definidas estas disciplinas, cada professor elaborou seu subprojeto com temática individual ou mesmo em parceria com outra disciplina/ professor, seguindo, logicamente, as definições estabelecidas no projeto integrador. Atualmente, o curso de Direito da UFN conta com oito disciplinas que fazem parte da curricularização da extensão. Tais disciplinas são ofertadas aos alunos do curso, na modalidade diurno e noturno, semestralmente, tendo, portanto, o envolvimento direto de dezesseis turmas e oito professores, bem como dos alunos matriculados. Importante referir ainda que diversos professores participam dos subprojetos auxiliando os professores da curricularização, seja coordenando junto as equipes, seja participando da orientação na produção de materiais, seminários, lives, entre outros.

Neste sentido, o presente artigo tem por objetivo apresentar o projeto integrador e os subprojetos desenvolvidos ao longo do tempo até o ano de 2020 no curso de Direito da UFN, adaptados para o momento pandêmico que assola a humanidade. Para tanto, dividiu-se o artigo em três partes. A primeira abordará a questão legislativa, a fim de definir quais são as métricas definidas pelo MEC para incrementar a extensão nas intuições de ensino superior brasileiras. No segundo tópico, será apresentado o projeto integrador do curso de Direto da UFN e os subprojetos desenvolvidos nas disciplinas. No terceiro, serão apresentados os resultados obtidos na efetivação das atividades, direcionadas totalmente para a virtualidade. 
Como metodologia, utilizar-se-á o método de abordagem dedutivo, pois partindo das definições estabelecidas pela legislação (geral), serão apresentados o projeto integrador do curso e os subprojetos das disciplinas extensionistas (particular). O método de procedimento foi o monográfico, porquanto lastreado em doutrina e legislação, assim como no material produzido pelos envolvidos. Como resultados obtidos, pode-se afirmar que o curso de Direito e seus professores e alunos conseguiram superar o período de crise instalado pela pandemia, construindo subprojetos inovadores, que cumpriram de forma excelente com as determinações do Ministério da Educação, reinventando a prática extensionista e provando que os períodos de crise são campo fértil para saídas criativas e inovadoras.

\section{A RESOLUÇÃO NÚMERO 07/2018 DO MEC E A EDUCAÇÃO NA PERSPECTIVA DA CONSTITUIÇÃO DA REPÚBLICA DE 1988}

A educação, conforme define a Constituição da República Federativa do Brasil de 1988, é um direito social. A primeira referência à educação no texto constitucional está no artigo $6^{\circ}$, dentro do Título II - Dos direitos e garantias fundamentais, inaugurando o rol elencado no Capítulo II - Dos direitos sociais.

A alocação da educação no Título II da constituição tem por objetivo deixar clara a intenção do legislador constituinte originário, porquanto, todos os direitos previstos no artigo $5^{\circ}$ (inclusive) até o 17 são cláusulas pétreas, ou seja, reforçam para a sociedade a importância desses direitos e, ao mesmo tempo, impõem ao legislador ordinário uma limitação no que tange ao poder de reforma constitucional, porquanto, o parágrafo $4^{\circ}$ do artigo 60 expressamente determina que "Não será objeto de deliberação a proposta de emenda tendente a abolir: I - a forma federativa de Estado; II - o voto direto, secreto, universal e periódico; III - a separação dos Poderes; IV - os direitos e garantias individuais.

Neste mesmo sentido, refere Moraes que "As limitações materiais, também denominadas de cláusulas pétreas, inibem a reforma constitucional sobre determinadas matérias, razão pela qual a emenda e revisão não pode recair sobre o cerne imodificável da constituição [...]” (MORAES, 2018, p. 55).

No que tange aos direitos sociais, J. A. Silva (2017, p. 288-289) explica que estes são “[...] prestações positivas proporcionadas pelo Estado direta ou indiretamente, enunciadas em normas constitucionais, que possibilitam melhores condições de vida aos mais fracos, direitos que tendem a realizar a igualização de situações sociais desiguais".

Portanto, a educação é um direito social, e, por estar elencada no título II (dos Direitos e garantias fundamentais) é cláusula pétrea, não podendo ser suprimida pelo legislador ordinário, porquanto, tem o claro objetivo de diminuir as desigualdades entre os cidadãos brasileiros, consistindo este em um compromisso do Estado. Ainda na perspectiva constitucional, é importante referir que as regras que dispõem sobre competências, concederam à União a incumbência de estabelecer as diretrizes e bases da educação nacional - (artigo 21, inciso XXIV, da Constituição). 
É com lastro nesta competência que o Ministério da Educação edita sua base regulamentar, que deve ser observada por todas as instituições de educação, nas quais se incluem as de ensino superior, atentando para as regulamentações específicas de cada área do conhecimento. Diante disso, a Resolução de número 07 de 2018 busca integrar o tripé que norteia o ensino superior no Brasil, qual seja, o ensino, a pesquisa e a extensão, dispondo que, no mínimo, 10\% da carga horária total curricular do curso seja composta de atividades extensionistas.

Imperatore (2019, p. 25) dialogando sobre a temática refere que "precisa-se de uma universidade corajosa, que invista na promoção da diversidade e no diálogo intercultural, e não se intimide ante às contradições e conflitos, naturalmente decorrentes dessa postura". O agir na curricularização da extensão impõe aos envolvidos - docentes e discentes, um fazer pedagógico diferente, que ao longo do caminho vai se construindo e se deparando com obstáculos que necessitam ser contornados.

Para Sousa (2010, p. 119) "A Universidade sempre esteve comprometida socialmente com alguém.” Está no cerne da Universidade trocar com à sociedade aquilo que ela saber fazer, que é a produção do conhecimento por meio do ensino, da pesquisa e da extensão. E é neste viés que o projeto integrador do curso de Direito da UFN tem buscado atuar.

Freitas et al. (2005, p. 77) pensando sobre as atividades extensionistas, diz que é fundamental que estas sejam vistas “[...] como possibilidades de transformação interna na Universidade, melhorando sua atuação junto à busca de soluções para os problemas existentes em comunidades carentes, por meio de políticas de saúde, educação, cidadania [...].” Assim, buscando efetivar tudo o que se apontou, é que o curso de Direito, por meio das destas disciplinas, teceu intervenções sociais que foram mediadas pelas Tecnologias da Informação e Comunicação - TICs, tendo em vista a pandemia da COVID-19.

Não é novidade que as atividades de ensino e pesquisa sempre demandaram maior atenção das Universidades, Centros Universitário e Faculdades, portanto, havia a necessidade de uma maior integração destes com a extensão. E essa lacuna é exatamente o espaço que deve ser preenchido pelas Instituições de Ensino Superior - IES na implementação da curricularização da extensão. Imperatore (2019, p. 153) refere que:

Curricularizar a extensão significa conceber um processo de aprendizagem que transcenda a mera transferência de conteúdos (ensino) e se reconfigure em conhecer para transformar, quer seja um epistemologia crítico-dialética conexa a aprendizagens experienciais. Pressupõe, portanto, transcender o ato educativo a contextos, conflitos e demandas reais que afiancem a interlocução dialógica universidade/ comunidade a partir do entrelaçamento de processos teóricos e práticos forjados na e pela práxis.

$\mathrm{O}$ artigo $5^{\circ}$ da resolução supracitada expressa que a concepção que estrutura as diretrizes da extensão na educação superior são: I - a interação dialógica da comunidade acadêmica com a sociedade por meio da troca de conhecimentos, da participação e do contato com as questões complexas contemporâneas presentes no contexto social; II - a formação cidadã dos estudantes, marcada e 
constituída pela vivência dos seus conhecimentos, que, de modo interprofissional e interdisciplinar, seja valorizada e integrada à matriz curricular; III - a produção de mudanças na própria instituição superior e nos demais setores da sociedade, a partir da construção e aplicação de conhecimentos, bem como por outras atividades acadêmicas e sociais; IV - a articulação entre ensino/extensão/pesquisa, ancorada em processo pedagógico único, interdisciplinar, político educacional, cultural, científico e tecnológico.

Deste modo, a promoção da educação deve ser fomentada tanto pelo Estado quanto pela sociedade, posto que a previsão dos artigos 205 e 206 da Constituição assim referem:

Art. 205. A educação, direito de todos e dever do Estado e da família, será promovida e incentivada com a colaboração da sociedade, visando ao pleno desenvolvimento da pessoa, seu preparo para o exercício da cidadania e sua qualificação para o trabalho.

Art. 206. O ensino será ministrado com base nos seguintes princípios:

I - igualdade de condições para o acesso e permanência na escola;

II - liberdade de aprender, ensinar, pesquisar e divulgar o pensamento, a arte e o saber;

III - pluralismo de ideias e de concepções pedagógicas, e coexistência de instituições públicas e privadas de ensino;

IV - gratuidade do ensino público em estabelecimentos oficiais;

V - valorização dos profissionais da educação escolar, garantidos, na forma da lei, planos de carreira, com ingresso exclusivamente por concurso público de provas e títulos, aos das redes públicas;

VI - gestão democrática do ensino público, na forma da lei;

VII - garantia de padrão de qualidade.

VIII - piso salarial profissional nacional para os profissionais da educação escolar pública, nos termos de lei federal.

IX - garantia do direito à educação e à aprendizagem ao longo da vida.

Parágrafo único. A lei disporá sobre as categorias de trabalhadores considerados profissionais da educação básica e sobre a fixação de prazo para a elaboração ou adequação de seus planos de carreira, no âmbito da União, dos Estados, do Distrito Federal e dos Municípios.

Portanto, a organização e as diretrizes da Educação no Brasil ficam a cargo do Estado, que, por meio do Ministério da Educação, conjuntamente com as famílias, deve se pautar nos princípios elencados no artigo $2^{\circ}$ da Lei número 9394/1996 - Lei de Diretrizes e bases da educação nacional: A educação, dever da família e do Estado, inspirada nos princípios de liberdade e nos ideais de solidariedade humana, tem por finalidade o pleno desenvolvimento do educando, seu preparo para o exercício da cidadania e sua qualificação para o trabalho.

Nas legislações referidas estão estruturados todos os níveis de educação do Estado brasileiro, devendo os princípios e regras estabelecidos serem observados por todos, com atenção especial aos regulamentos próprios. Desse modo, a UFN tem cumprindo as determinações ministeriais, e implantou em seus cursos a curricularização da extensão, sendo o tópico seguinte dedicado a análise do projeto integrador do curso de Direito e seus subprojetos. 


\section{O PROJETO INTEGRADOR DO CURSO DE DIREITO E OS SUBPROJETOS}

O Curso de Direito da Universidade Franciscana em seu Projeto de Extensão Integrador, intitulado "Direito constitucional aplicado, gestão de pessoas e processos" tem por justificativa compreender como estão sendo, ou não, efetivadas as promessas constitucionais estabelecidas pelo Legislador Constituinte Originário, observando que, durante todo o século XX, inúmeras foram as transformações sociais experimentas, que "evidenciam a necessidade da conjugação de esforços de todos os atores sociais para sua concretização, o que oportuniza espaços privilegiados de intervenção da academia" (PROJETO INTEGRADOR DIREITO - PI DIREITO, 2021). Neste sentido, a academia tem papel singular, porquanto deve, além de realizar o diagnóstico dessas necessidades, também propor alternativas de enfrentamento, sempre em interlocução constante com a comunidade, numa verdadeira abordagem dialogada entre a teoria e a prática.

Em vista disso, o projeto integrador do Curso de Direito da UFN (2021), entende que é essencial esse "construir coletivamente", formando uma nova forma de pensar e operacionalizar o Direito com "caráter extensionista, comprometido com os valores e princípios que inspiram o Estado Democrático de Direito, com capacidade para impulsionar novas práticas que conduzam ao desenvolvimento local e regional".

Para tanto, tem como objetivo, alinhado ao projeto pedagógico do Curso e aos documentos institucionais, estabelecer/construir "novas formas de atuação acadêmica de caráter extensionista, com viés multidisciplinar, sensíveis às demandas da Sociedade e orientadas pelos valores constitucionais que norteiam o Estado Democrático de Direito [...]” (PI DIREITO, 2021). Ademais, objetiva-se ainda, por meio da prática extensionista na graduação, que os alunos tenham uma formação integral, condizente com a prática profissional que experimentarão como bacharéis em Direito.

Em seus delineamentos, o projeto integrador (2021) intenciona a formação de "recursos humanos qualificados e sensíveis à realidade local e regional, com habilidade para atuação jurídica numa perspectiva multidisciplinar" estando apto a desenvolver competências para atuar a partir da nova concepção de constitucionalismo, "a qual engloba além da noção de Constituição garantia também a de Constituição como diretiva fundamental” (PI DIREITO, 2021).

O Projeto integrador do curso de Direito foi pensado como um grande estruturador de tudo que o curso pensa sobre extensão. Após sua definição, foram escolhidas, por meio do Núcleo Docente Estruturante - NDE, quais as disciplinas que tinham o perfil para realizarem essa integração entre teoria e prática de forma mais completa e promissora. A partir da escolha das disciplinas, cada professor deve elaborar um subprojeto, alinhado ao projeto integrador e também ao seu conteúdo programático. Os subprojetos estão abrigados no integrador e só existem quando estão adequados a ele. Ou seja, as linhas mestras da curricularização da extensão no curso são definidas pelo projeto integrador. 
Assim, o projeto integrador do Curso de Direito busca, por meio do desenvolvimento dos subprojetos de cada uma das disciplinas extensionistas, um diálogo permanente e qualificado com a Comunidade de Santa Maria e da região. No âmbito do curso de Direito, oito disciplinas estão elencadas como componentes da curricularização da extensão, cujos subprojetos são desenvolvidos no curso diurno e noturno, o que faz com que dezesseis turmas participem ativamente de todas as atividades propostas a cada semestre.

Durante o primeiro semestre do ano de 2021, oito foram as disciplinas da curricularização: Extensão em Direito I; Direito das Crianças e Adolescentes; Direito do Consumidor; Gestão de Conflitos; Extensão em Direito II, Direito das Famílias, Direito Ambiental e Direito da Seguridade Social.

Contudo, desde o início do ano de 2020, os professores titulares dessas disciplinas, têm sido desafiados. Com a declaração pela Organização Mundial da Saúde - OMS da pandemia do novo coronavírus, em um espaço curto de tempo, os professores e alunos precisaram se readequar. Com a suspensão das aulas presenciais e o distanciamento social imposto pelo Estado, pensou-se que seria impossível realizar extensão. Todavia, professores quando são instigados, fazem sua criatividade aflorar. E foi exatamente isso que tem ocorrido.

As práticas extensionistas foram inovadas a partir de uma nova realidade global, o que exigiu uma readequação na postura dos docentes e dos discentes, pois precisaram realizar extensão sem contato com as comunidades e territórios mapeados, o que implicou em não ter a participação direta desses sujeitos, essenciais aos subprojetos. Nessa reinvenção necessária, as plataformas digitais foram aliadas para, de algum modo, aproximar a sociedade da universidade, fazendo com a prática extensionista não fosse abandonada ou relegada a um segundo momento, mas sim, que esta fosse realinhada, adaptada para atender uma demanda ainda desconhecida, desafiadora, mas extremamente conectada com a sociedade e seus problemas.

Neste sentido, importante mencionar, mesmo que sinteticamente, os subprojetos desenvolvidos em cada uma das oito disciplinas que integram a curricularização do curso de Direito. A primeira é a disciplina Extensão em Direito I, que tem por objetivo preparar os alunos por meio da consolidação da teoria para as práticas extensionistas. Esta disciplina localiza-se no $3^{\circ}$ semestre do curso e é a primeira das disciplinas elencadas como de curricularização da extensão. É uma disciplina de base, que prepara os discentes para as demais.

A disciplina de Direito da Criança e do adolescente está alocada também no $3^{\circ}$ semestre do curso e vem sendo desenvolvida por meio remoto devido ao período da pandemia. Sob a temática da criança e do adolescente foram pesquisadas as temáticas: 1) Menor, por que não devemos usar este termo?; 2) Termos apropriados para se dirigir à criança e ao adolescente; 3) Diga não à violência sexual infantil!; 4) Você já ouviu falar em aliciamento online de crianças e adolescentes?; 5) Segurança digital infantil; 6) Castigo físico não educa; 7) Você sabe o que é trabalho infantil?; 8) Saúde da 
criança e do adolescente na era digital; 9) Direito à saúde bucal; 10) O abuso sexual como forma de alienação parental; 11) Viagens com crianças e adolescentes.

A disciplina de Direito do Consumidor, situada no $4^{\circ}$ semestre do curso de Direito, tem como tema central a produção de conteúdo sobre educação financeira e consumo responsável no perfil do EDUCON que tem página no Instagram (@educonufn). Os alunos também se dedicaram a pesquisa sobre o endividamento das famílias brasileiras durante a pandemia, com produção de conteúdo e divulgação de gráficos.

O professor da disciplina de Direito do Consumidor também criou o COVIDIR - Observatório Jurídico da Pandemia, que tem por objetivo a reprodução e publicação de discussões e proposições nas diversas áreas jurídicas diante dos efeitos e impactos atuais e futuros da pandemia do Corona Vírus. O COVIDIR está hospedado no Blog do Observatório de Direitos Humanos do Curso de Direito e, desde a sua construção, publicou vinte e cinco textos, que são selecionados e estudados pelos professores do Curso de Direito, que, quando entendem que o material é pertinente, encaminham para publicação no blog, conseguindo o projeto a união e apoio de todo corpo docente do curso. $\mathrm{O}$ projeto, pensado em meio a necessidade de se esclarecem dúvidas sobre os reflexos da pandemia nas relações de direito, tem sido um importante canal na busca de informações e esclarecimentos, tanto para alunos e professores como para a comunidade externa.

As disciplinas de Gestão de Conflitos e Extensão Em Direito II foram trabalhadas em conjunto pelos professores, que criaram o CORONA-JUR - canal jurídico da UFN no combate à pandemia da COVID-19. Este canal tem por objetivo oportunizar à comunidade uma orientação na solução dos seus problemas jurídicos ocasionados pela pandemia. A união das duas disciplinas possibilitou que os alunos aplicassem, junto as informações jurídicas, as teses de gestão de conflitos, o que deixou evidente na execução a interdisciplinaridade entre as duas disciplinas, com ganho qualitativo significativo para o corpo discente.

A disciplina de Direito das Famílias está localizada na matriz curricular no $7^{\circ}$ semestre. O subprojeto trata dos efeitos da pandemia e do isolamento social nas relações familiares sob o título "Quem ama cuida". Utiliza o Facebook e o Instagram como ferramentas principais para divulgação do material produzido (cards e lives) que versam sobre as relações filiais.

A disciplina de Direito Ambiental está alocada no $9^{\circ}$ semestre da matriz curricular do curso. O subprojeto aqui desenvolvido tem por objetivo a assistência jurídica gratuita ambiental para prestar consultorias, pareceres e assessorias a associações civis ambientais sem recursos, pequenos produtores rurais, catadores, população de baixa renda, visando a proteção ao patrimônio histórico cultural e ecológico, tendo em vista que a região de Santa Maria encontra-se cercada de áreas de preservação permanente. Como são vários os atores envolvidos no ecossistema, importante dialogar com aqueles que, muitas vezes, não tem acesso às informações e, tampouco a ferramentas jurídicas, capazes de albergar suas necessidades ou mesmo evitar conflitos com a legislação ambiental. 
Por fim, a disciplina de Seguridade Social tem por objetivo, em seu subprojeto, auxiliar as pessoas da comunidade a conhecer os serviços prestados pelo Instituto Nacional da Seguridade Social - INSS, por meio do acesso à plataforma meu INSS. Esse subprojeto tem, junto aos demais, uma relevância indiscutível, haja vista que atende diretamente as pessoas hipossuficientes que necessitam dos auxílios previdenciários nestes tempos pandêmicos.

Pelo exposto, pode-se afirmar que os subprojetos das disciplinas integrantes da curricularização da extensão no curso de Direito da UFN está perfeitamente alinhada com o projeto integrador, seguindo suas premissas e objetivos, alcançando resultados além dos inicialmente esperados, como ser relatado no tópico que segue.

\section{RESULTADOS ATINGIDOS NO ÂMBITO DA CURRICULARIZAÇÃO DA EXTEN- SÃO NO CURSO DE DIREITO DA UFN}

A pandemia do novo coronavírus surpreendeu a todos. Vivenciar uma pandemia era coisa que a grande maioria da população mundial ainda não tinha experimentado. Medo diante do desconhecido, incertezas sobre as questões cotidianas, receio de sair às ruas, distanciamento das famílias e amigos. Os efeitos desses dezesseis meses ainda estão sendo vivenciados. A pandemia exigiu de todos a adoção de uma nova postura, pois não se podia mais agir como outrora.

As consequências deste período já foram sentidas logo no início, mas a longo prazo, serão ainda maiores as sequelas. Problemas financeiros e psicológicos, agravados pela perda de pessoas queridas, mexeram com o emocional de todos.

Como se não fosse suficiente tudo o que estava acontecendo no mundo, vem a suspensão das aulas no Brasil e com isto, mais incertezas e insegurança. Como fazer extensão remotamente? Como integrar universidade e comunidade de forma on-line? Como cumprir o papel social da instituição e do curso diante da impossibilidade do contato físico?

Todas essas questões perpassaram pela cabeça dos professores e gestores. Mas como era de se esperar, passado a apreensão inicial, as ideias começaram a surgir, a troca com os alunos foi gerando reação, e a reação virou motivação e de um período de crise floriu a criatividade, a vontade de fazer mesmo em condições adversas e muito se produziu.

As disciplinas da curricularização da extensão do curso de Direito da UFN produziram tantas e tão belas coisas que merecem ser divulgadas. Quase todos os subprojetos realizaram lives, transmitidas ao vivo pelo Instagram do Laboratório de Extensão ou mesmo nas páginas individuais dos subprojetos, que, dentro da temática específica de cada disciplina e subprojeto, trouxe convidados com expertise em suas áreas para abordar as temáticas elegidas. As lives eram divulgadas por meio de postagens que informavam sobre as temáticas debatidas, o horário e os nomes dos convidados. Com efetiva participação da comunidade, essa atividade foi um sucesso, atingindo público super relevante. 
Também foram realizadas aulas abertas, transmitidas via Google Meet para toda a comunidade interna da UFN e também externa, uma vez que contou com a participação de alunos de outras instituições de ensino superior.

Na disciplina de Extensão em Direito II e Gestão de Conflitos, foi criado pelos professores responsáveis o CORONAJUR - canal jurídico da pandemia. Aqui os alunos se dividiram em equipes e escolheram para realizar suas atividades os temas que tiveram impacto relevante com a pandemia, como o Direito das Famílias, o Direito Penal, o Direito do Trabalho entre outros (foram quatorze grupos de trabalho criados dentro do subprojeto). Cada grupo foi orientado por um professor, a escolha do grupo e desde que afeto a temática proposta. Os alunos criaram cards explicativos dos conteúdos que foram disponibilizados nas redes sociais, e tinham por objetivo sanar as dúvidas sobre o assunto. Neste mesmo subprojeto projeto também foram realizadas diversas lives.

$\mathrm{Na}$ disciplina Direito da Criança e do Adolescente os alunos realizaram pesquisas sobre temas previamente definidos por estes, por meio da mediação da professora da disciplina. Foram produzidos infográficos, cartazes e vídeos, buscando esclarecer a sociedade sobre temas absolutamente essenciais com relação a este público. Os materiais foram publicizados na página do Observatório de Direito Humanos do Curso de Direito da Universidade Franciscana e também na página do Instagram do Laboratório de Extensão do Curso e tem, e como público atingido uma média de cem famílias.

A disciplina de Direito do Consumidor, situada no $4^{\circ}$ semestre do curso, teve como tema central a produção de conteúdo sobre educação financeira e consumo responsável. Todos os materiais foram disponibilizados no perfil do EDUCON no Instagram (@educonufn). O subprojeto tem por objetivo atuar na prevenção e tratamento do superendividamento do consumidor, temática já desenvolvida no Curso de Direito da Universidade Franciscana há mais de 10 anos, onde funciona o Centro de Prevenção e Tratamento do Superendividamento (Convênio da UFN e Prefeitura Municipal que estabelece cooperação técnica no Programa Municipal de Proteção ao Consumidor - PROCON).

A proposta do EDUCON se estrutura em três frentes: prevenção, tratamento e produto. A prevenção consiste na realização de atividades com o grupo em atendimento e com a população em geral, por meio de oficinas, material informativo digital e impresso e criação de um perfil na rede social Instagram para produção e divulgação de conteúdo sobre educação financeira. O tratamento se dá a partir do atendimento aos consumidores, que apresentam as duas demandas de (sobre)endividamento, sendo que o processo tem início por meio de reunião de acolhimento, entrevista e audiência para elaborar Plano de Pagamento e Recuperação de Crédito, que no momento pandêmico precisou ser readequada para a realidade online. Quanto ao produto, este é resultado das entrevistas e também das audiências, que produzem material extremamente rico e que possibilita que seja traçado um perfil dos atendidos no projeto, gerando ainda uma amostra dos consumidores endividados no Município de Santa Maria-RS. Assim, com base nos atendimentos e nos dados existentes dos últimos anos do projeto, são elaborados gráficos para divulgação e publicação de obra/livro que comemora os 10 anos 
do projeto, constituindo o produto final do Observatório do Crédito e Superendividamento. O subprojeto desenvolveu ainda ações de participação cidadã voltadas para a aprovação do Projeto de Lei atualização do Código de Defesa do Consumidor.

Os alunos, juntamente com o professor, produziram materiais informativos extremamente qualificados e, alem da repercussão regional, o projeto teve projeção nacional por meio da entrevista do professor responsável no Jornal Nacional da Rede Globo.

Na disciplina de Direito das Famílias, pertencente ao $7^{\circ}$ semestre, o tema do subprojeto é a convivência parental e a conscientização da importância da guarda compartilhada como prevenção à alienação parental e ao abandono afetivo na sua primeira versão. Atualmente, o subprojeto é denominado "Quem ama cuida". O subprojeto tem por objetivo aplicar a prática extensionista junto à disciplina de Direito das Famílias, com vistas a formar operadores jurídicos sensíveis aos problemas e atentos na busca de resoluções, intervindo na comunidade local e regional, na busca da cultura pela paz nas relações parentais, por meio da conscientização da importância da guarda compartilhada como meio de prevenção à alienação parental e ao abandono afetivo, bem como todas as demais temáticas que dizem respeito a relação entre pais e filhos. O subprojeto produziu lives e materiais informativos que foram socializados nas redes sociais.

A penúltima das disciplinas integrantes da Curricularização da Extensão é o Direito Ambiental que se encontra no $9^{\circ}$ semestre da matriz curricular do curso. O subprojeto está em andamento desde o primeiro semestre de 2020 e, em um primeiro momento, os alunos mapearam as principais entidades que formariam o público alvo da Assistência Judiciária Gratuita em Direito Ambiental. Foram doze entidades mapeadas e, desde o semestre em curso, o objetivo do subprojeto é verificar as demandas dessas entidades para então atender, de forma gratuita suas demandas judicias.

Por fim, a oitava disciplina integrante da curricularização da extensão é o Direito da Seguridade Social, alocada no $10^{\circ}$ semestre do curso. A disciplina foi a última dar início aos trabalhos na curricularização, tendo em vista a implementação da nova matriz curricular do curso, que entrou em vigência em 2016, sendo que apenas neste momento foi ofertada nesse formato. A proposta do subprojeto é ser um canal de informação da população no que tange ao esclarecimento do uso do aplicativo do INSS, chamado "Meu INSS", e tem por escopo tirar as dúvidas de todos aqueles que precisam acessar os serviços do órgão previdenciário, tão demandado neste momento de pandemia. O subprojeto esta produzindo muitos materiais informativos, que servem efetivamente para auxiliar as dúvidas da população.

Perpassados todos os subprojetos, é possível afirmar, que há absoluta sintonia entre o que está previsto no projeto integrador e o que vem sendo realizado dentro dos subprojetos de cada uma das disciplinas da curricularização da extensão. Ademais, o momento de pandemia, que inicialmente chegou a ser uma interrogação sobre a continuidade dos projetos acabou por, de forma natural, propiciar uma redefinição de rumos, com todos os alunos e professores envolvidos nestas disciplinas cuidando 
de aspectos socialmente relevantes e perfeitamente aliados com a realidade prática. Todos precisaram se reinventar e, nessa reinvenção imposta pela crise sanitária mundial, fez com que o olhar de cuidado com o próximo ficasse ainda mais atento, mais meticuloso, mais humano. Se a curricularização da extensão tem por objetivo aliar a teoria à prática, o curso de Direito fez mais, aliou a teoria e a prática à formação de seres humanos melhores, mais conectados com a realidade do seu entorno, mais preocupados com o problema alheio, mais abertos ao acolhimento. Mesmo sem estar presente nas comunidades o curso de Direito se fez presente na sociedade. O isolamento físico trouxe a proximidade das ideias, das intenções, das realizações. O avanço foi incrível, mas este é só o começo.

\section{CONCLUSÃo}

A curricularização da extensão foi determinada por meio da Resolução no 07/2018 e veio para efetivar a prática extensionista dentro dos cursos superiores. Quando da sua publicação, causou preocupação a todos os gestores de Universidades, Centros Universitários e Faculdades, porque o desafio era imenso e as dúvidas ainda maiores.

Após muito estudo e análise, entendeu-se que cada curso deveria criar um grande projeto guarda-chuva, que foi nominado de projeto integrador e, posteriormente, as disciplinas extensionistas deveriam elaborar seus próprios subprojetos, estando, evidentemente, adequados as diretrizes trazidas pelo projeto integrador. Superada a fase das discussões legais e procedimentais, era hora de colocar em prática o desenvolvimento dessas ideias.

Com algum medo, muita desconfiança e uma certa dose de coragem, os subprojetos começaram a ser efetivados. Quando se pensou que o processo estava dominado, veio a crise sanitária mundial, que colocou em xeque tudo que até então fora desenvolvido. Novos rumos precisaram ser traçados e o desafio de se fazer extensão online foi assustador. Ao mesmo tempo que era necessário cumprir com as determinações do Ministério da Educação no que tange a institucionalização da extensão, se questionava sobre o como. Como fazer extensão sem inserção nas comunidades foi um grande desafio, intelectual e emocional, que precisou ser superado pelos atores envolvidos.

Adequando-se todos os subprojetos, vinculados ao projeto integrador, e, passados mais de dezesseis meses do isolamento físico, pode-se afirmar, sem qualquer receio, que os objetivos traçados foram alcançados. Mesmo que a adaptação para o momento de crise sanitária tenha exigido um modelo diferente de extensão, sem a integração pessoal dos envolvidos no local da intervenção, se fez extensão de qualidade.

Os subprojetos atenderam as mais variadas demandas sociais. Alunos e professores se fizeram presentes mesmo que online. A teoria e a prática foram aliadas de forma indissolúvel e indissociável. É possível fazer extensão mesmo nas adversidades. 
O projeto integrador do Curso de Direito prevê, como resultado a ser atingido, a contribuição para a formação de novo perfil acadêmico extensionista, com atenção os anseios da sociedade, propondo práticas voltadas à interação entre a Universidade e a Sociedade para uma construção coletiva de produtos e serviços que atendam as necessidades locais e regionais, com potencial para transformar a realidade. Tais objetivos foram atingidos de forma excelente, o que se comprova pela quantidade de materiais produzidos e o alcance deste para as comunidades locais e regionais.

O uso das Tecnologias da informação e Comunicação formam essenciais para que se produzisse o tanto que se produziu, com a qualidade que se produziu. Passado o susto inicial, se percebe o quanto todos evoluíram nesse período, seja pelas mudanças impostadas pela pandemia, seja pelo que se fez para auxiliar os mais variados públicos. Ficou evidenciada a importância da universidade como ator na divulgação do conhecimento e da informação. Ficou evidente também como, em meio a tanta tristeza e descontentamento, se pode ajudar ao próximo e ainda colher belíssimos resultados. Se hoje me perguntassem se é possível fazer extensão online, responderia sem titubear, não só é possível como é essencial.

\section{REFERÊNCIAS}

BRASIL. Constituição da República Federativa do Brasil de 1988. Disponível em: https://bit.ly/ 3pjzlBz. Acesso em: 22 mai. 2021.

FREITAS, Ayres Borges; PRADO, Carlos Roberto do; SILVA, Eunice Souza da, et al. Extensão Universitária: Construção de Solidariedade. São Paulo: Expressão e Arte, 2005

IMPERATORE, Simone Loureiro Brum. Curricularização da Extensão - experiência da articulação extensão-pesquisa-ensino-extensão como potencializadora da produção e aplicação de conhecimento em contextos reais. Rio de Janeiro: Gramma, 2019.

MORAES, Guilherme Peña de. Curso de Direito Constitucional. 10. ed. São Paulo: Atlas, 2018.

PROJETO INTEGRADOR DO CURSO DE DIREITO DA UFN. Documento interno, não acessível a todos.

SILVA, José Afonso da. Curso de Direito Constitucional Positivo. 40. ed. São Paulo: Malheiros, 2017.

SOUSA, Ana Luiza Lima. A História da Extensão Universitária. 2. ed. Campinas: Alínea, 2010. 